\title{
Ovarian torsion in a prepubertal girl
}

\author{
Brian T. Kloss • Louise A. Prince
}

Received: 21 December 2008 / Accepted: 17 February 2009/Published online: 24 March 2009

(C) Springer-Verlag London Ltd 2009

A previously healthy 4-year-old female presented to the Emergency Department complaining of sudden-onset rightlower-quadrant abdominal pain that awoke her from sleep. The pain was constant, non-radiating and severe. She denied trauma, dysuria, hematuria, nausea, vomiting,

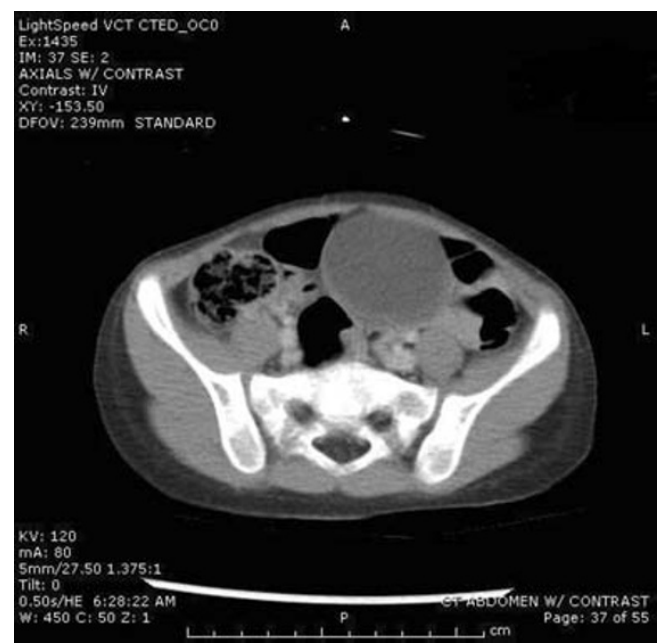

Fig. 1 Transverse CT image

B. T. Kloss $\cdot$ L. A. Prince

The Department of Emergency Medicine,

The State University of New York, Upstate Medical University, Syracuse, NY, USA

\section{B. T. Kloss $(\bowtie)$}

Department of Emergency Medicine,

SUNY Upstate Medical University,

750 East Adams St,

Syracuse, NY 13210, USA

e-mail:klossb@upstate.edu

e-mail: klossy007@aol.com diarrhea, constipation or hematochezia. Her vitals were HR: 92, RR: 16, BP: $116 / 76$ and T: $37.0^{\circ} \mathrm{C}$. Physical exam revealed tenderness at McBurney's point, but no rebound, rigidity or guarding. $\mathrm{CBC}$ with differential, basic metabolic panel and urinalysis were all unremarkable. A CT abdomen with contrast and ultrasound revealed a $5.0 \times 4.2 \times 4.8-\mathrm{cm}$ non-communicating cystic mass abutting the left dome of the bladder. The differential diagnosis included mesenteric cyst, enteric duplication cyst, urachal cyst and ovarian cyst. Surgical exploration confirmed the diagnosis of right ovarian cyst with torsion. Kokoska et al. reviewed 51 cases of ovarian torsion between 1983 and 1999 and reported the mean age to be $12.5 \pm 1.3$ years [1]. A similar study by Anders et al. reviewed 22 cases and calculated the mean age to be 10.2 years with a range of $3-15$ years [2]. Ovarian

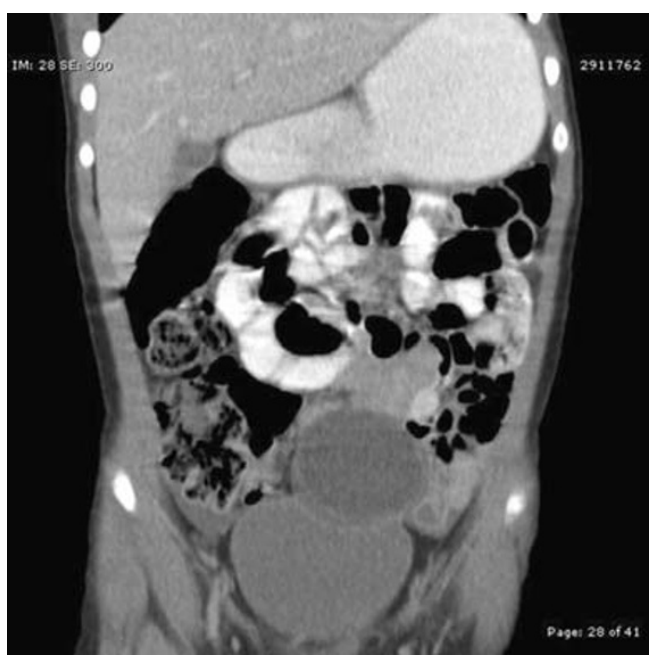

Fig. 2 Coronal CT image 


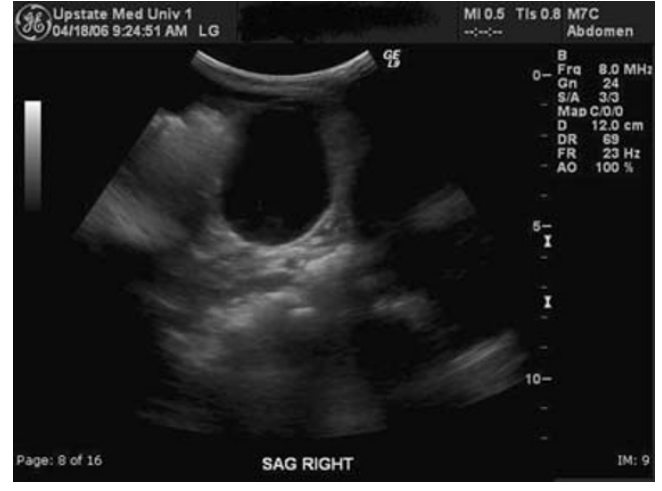

Fig. 3 Abdominal US image torsion is a rare, but important cause of abdominal pain in younger children that requires a high index of suspicion (Figs. 1, 2 and 3).

\section{References}

1. Kokoska ER, Keller MS, Wever TR (2000) Acute ovarian torsion in children. Am J Surg 180(6):462-465

2. Anders JF, Powell EC (2005) Urgency of evaluation and outcome of acute ovarian torsion in pediatric patients. Arch Pediatr Adolesc Med 159(6):532-535 